\title{
The capacitive sensing of NS1 Flavivirus biomarker
}

\author{
Juliana Cecchetto, Flávio C.B. Fernandes, Rute Lopes, Paulo R. Bueno* \\ Institute of Chemistry, Univ. Estadual Paulista (UNESP, São Paulo State University), Nanobionics group (www.nanobionics.pro.br) CP 355, CEP 14800-900, \\ Araraquara, São Paulo, Brazil
}

\section{A R T I C L E I N F O}

\section{Keywords:}

Electrochemical capacitance spectroscopy

Electrochemical impedance spectroscopy

Flavivirus

Dengue

NS1

\begin{abstract}
A B S T R A C T
NS1 is a biomarker for different Flavivirus diseases such as dengue (DENV), zika (ZIKV) and chikungunya (CHIKV) and was herein selectively quantified by electrochemical capacitive sensing (an impedance-derived capacitance methodology wherein the redox probe is contained in the receptive layer) mainly aiming dengue diagnosis in phosphate buffer saline and blood serum environments (up to the neat level). The capacitive sensing was compared to traditional concurrent impedimetric approach (in which the redox probe is added in the biological solution) and other transient methods stated in the literature regarding figures of merit such as limit of detection, linear range, relative standard deviation and affinity constant. Capacitive and impedimetric assays showed equivalent results for linear range, repeatability, sensitivity and constant of affinity. Nonetheless capacitive assays presented better reproducibility with a relative standard deviation (RSD) of $3 \pm 1$ and $7 \pm 4$ (all in percentage) in PBS and serum, respectively, meanwhile for impedimetric assays the RSD values were $9 \pm 5$ in PBS and $12 \pm 6$ in serum. Thus, by using capacitive assays, an improvement on the analytical performance was observed with the limit of detection about sixty-fold lower in neat serum $\left(\sim 0.5 \mathrm{ng} \mathrm{mL}{ }^{-1}\right.$ for capacitive over $\sim 30 \mathrm{ng} \mathrm{mL}^{-1}$ for impedimetric assays) compared to traditional electrochemistry methods in general hence demonstrating the superior detection sensitivity for NS1 protein. Accordingly, redox tagged capacitive assays are suitable for the development of multiplex point-of-care neglected diseases sensing applications.
\end{abstract}

\section{Introduction}

Dengue is a non-contagious infectious disease caused by a virus (DENV), classified under the Flavivirus genus, transmitted by the bite of infected Aedes genus mosquito, mainly in tropical and subtropical regions (Guzman et al., 2010). There are different serotypes of the virus (DENV-1, DENV-2, DENV-3 and DENV-4), all of them have the ability to produce infections (Bhatt et al., 2013). Climate changes with increasing temperatures in temperate regions of the globe are enhancing the risk of re-emergence of dengue in Europe, in the manner of the outbreak in 2012 in Madeira, Portugal, the first since the 1920s (LiuHelmersson et al., 2016). Other factors associated with globalization, such as trade and air travel, have caused an impact on the increasing number of dengue cases in the United States as well (Fredericks and Fernandez-Sesma, 2014). In recent decades the global incidence of dengue has grown dramatically, implicating it to be considered the most important arboviral disease (World Health Organization., 2016). According to Bhatt et al. (2013), there should be an increase of 390 million cases of dengue infections per year worldwide, of which 96 million manifest at any level of severity, and that is more than three times the burden estimate of the World Health Organization for the year of 2009 (Bhatt et al., 2013); a discrepancy that might be explained by asymptomatic or mild cases that may not have been officially notified. In Brazil alone, over a million cases of dengue were registered from January to May of 2015 (Pan American Health Organization., 2015).

Laboratory methodologies for diagnosis of dengue comprise essentially virus isolation, which provides a direct, specific and conclusive response, however it requires high level equipment, technical expertise, it is a lengthy procedure and, in addition, it does not provide a differentiation between first and second infections (Klungthong et al., 2007). Viral nucleic acid detection, which is based on molecular techniques such as real time reverse transcription polymerase chain reaction (rt-PCR) and nucleic acid sequence based amplification (NASBA), provides a rapid identification and diagnosis of DENV serotypes, nevertheless the disadvantages include false positive results due to sample contamination, relatively high cost and also it does not allow to distinguish between first and second infections (Subedi and Taylor-Robinson, 2014). Serological analyses of the antigen/antibody responses, such as enzyme-linked immunosorbent assay (ELISA), are efficient methods that additionally present great sensitivity. Nonetheless, ELISA has disadvantages regarding the difficulty of

\footnotetext{
* Corresponding author.

E-mail address: prbueno@iq.unesp.br (P.R. Bueno).
} 
interpretation between serotypes since low levels of IgM are sometimes undetectable in secondary infections, and past or recent infections can produce cross-reactivity to different Flavivirus antigens (Peeling et al., 2010; Shu and Huang, 2004; Subedi and Taylor-Robinson, 2014).

Diagnosis of diseases can also be achieved by the quantification of specific biomolecules (biomarkers), or else their simple presence might be an indication of some related pathological event (Sadana and Sadana, 2015; Sahab et al., 2007). For instance, the non-structural protein NS1 is encoded by the Flavivirus genome, and it is considered a biomarker for several of them (Muller and Young, 2013). NS1 exists in multiple oligomeric forms with molecular weight ranging from 46 to $55 \mathrm{kDa}$, depending on its glycosylation patterns, that are dependent on the infecting Flavivirus and on the host cells they infect and their different cellular locations (Muller and Young, 2013). Indeed, NS1 detection has gained considerable attention for early diagnostic tests of dengue infection, as it is found in abundance in the serum of patients through early stages of the disease (Parkash and Hanim Shueb, 2015) and consequently many works have been proposed to evaluate the levels of NS1 antigen in buffer and in serum samples (Cavalcanti et al., 2012; Dias et al., 2013; Figueiredo et al., 2015; Silva et al., 2014; Su et al., 2003). Although some authors have reported higher levels of NS1 in secondary infections due to increased viremia (Dussart et al., 2006), others describe the detection of this protein due to low pre-existing virus-IgG immune complexes (Peeling et al., 2010). Independently of the contradictions (Vazquez et al., 2010), these works are sustained on low detection limits of NS1, thus seeking for a diagnostic assay able to qualify the dengue infectious phase.

Similarly, according to the Centers for Disease Control and Prevention, zika virus (ZIKV) infection can be diagnosed during the first week of the appearance of the first symptoms, and the usual methods performed up to date are rt-PCR and zika MAC-ELISA, the latter based on the capture of IgM in serum or cerebrospinal fluid specimens (Centers for Disease Control and Prevention, 2016; Lanciotti et al., 2008). The symptoms for DENV, ZIKV and chikungunya (CHIKV) virus infections are very similar; they may include fever, headache, myalgia, conjunctivitis, pruritus, vomiting, diarrhea, anorexia and abdominal pain. Therefore, the clinical analysis isolated may lead to a misdiagnose, and the laboratorial diagnose is paramount to define the course of treatment and for epidemiological purposes (Estofolete et al., 2016).

Cheaper, faster, simpler, more specific and sensitive methods to map the entire picture of dengue or zika epidemic are thus of utmost importance, especially in developing countries as a way to provide an efficient diagnosis of dengue or zika, for prevention and/or to keep the epidemic center under control and containment. In the quest to develop new methodologies, the ones potentially point-of-care (or bedside), miniaturized and highly efficient are crucial. Electroanalytical methods are promising to underpin progress concerning the next generation of biomarker assays toward obtaining increasingly sensitive, multiplexed and portable biosensing configurations (Patil et al., 2014). Electrical assays support an easy integration with standard microfabrication and microfluidic formats, and yield electroanalysis designs with low cost, high throughput, high innate sensitivity and capability for simultaneously quantifying multiple biomarker targets on a chip (Bryan et al., 2013; Chikkaveeraiah et al., 2012, 2011; Luo and Davis, 2013).

Across the board, electroanalytical assays use voltage and current input/output signals. In other words, a current/voltage is applied on a target-receptive electrode (input) and a correspondent voltage/current is measured as the output signal. Voltage input setup (with current output signal) is the most used configuration for biomarker detection, e.g. in voltammetric methods that include linear sweep (Yan et al., 2010), differential pulse (Pournaghi-Azar et al., 2009) square wave (Li et al., 2011), amperometry (Telsnig et al., 2012) etc. In this sense, many existing output techniques combined to different nanostructure of the receptive surfaces have been applied in the development of methodologies for monitoring NS1 antigen levels. For example, Cavalcanti et al. (Cavalcanti et al., 2012) proposed an electrochemical immunosensor with anti-NS1 monoclonal antibodies immobilized via protein A to detect NS1 protein in serum using differential pulse voltammetry (DPV) as the current output signal technique. The measurements used $\left[\mathrm{Fe}(\mathrm{CN})_{6}\right]^{3-/ 4-}$ in solution as signal amplifier and the obtained limit of detection (LoD) was $0.33 \mathrm{ng} \mathrm{mL}^{-1}$ (Cavalcanti et al., 2012). Dias and collaborators (Dias et al., 2013) developed an indirect and label-based method for NS1 protein detection using carbon nanotube-screen printed electrodes (CNT-SPE) with amperometric measurements. The amperometric responses were generated by hydrogen peroxide reaction with peroxidase (HRP) conjugated to antiNS1 with limit of detection with LoD in the order of $12 \mathrm{ng} \mathrm{mL}^{-1}$ (Dias et al., 2013). Voltage output techniques, where the open circuit potential (OCP) was used as signal transducer, were also applied to detect NS1 protein by disposable Au electrodes containing immobilized anti-NS1. Although the method is label-free and requires no signal amplifiers it showed a limited LoD of $90 \mathrm{ng} \mathrm{mL}^{-1}$ and correlation coefficient $\left(\mathrm{R}^{2}\right)$ of 0.96 (Figueiredo et al., 2015). Despite of the advantages of the above mentioned methods, the use of signal amplifiers in the biological sample/solution (Cavalcanti et al., 2012), the use of protein labeled components as well as indirect detection (Dias et al., 2013) or limited sensitivity (Figueiredo et al., 2015) certainly leaves room for improvements.

Therefore, spectroscopic electroanalytical methods are particularly noteworthy because it is uniquely non-destructive, topologically flexible, and sensitive to changes at a receptive interface without requiring any amplification or the labeling of the target or the receptive species (Daniels and Pourmand, 2007; Lin et al., 2013; Ohno et al., 2013; Sahoo et al., 2013; Venkatanarayanan et al., 2013).

Furthermore, electroanalytical spectroscopy can provide an interesting alternative aiming NS1 detection and can be classified as impedimetric (EIS) (Patil et al., 2014) and capacitive (ECS) (Bueno et al., 2012), in which ECS is a relatively different approach compared to EIS regarding the interfacial properties of modified electrodes (Bueno et al., 2012; Fernandes et al., 2014). EIS can still be divided into faradaic (with a redox probe present in the analytical solution) (Bryan et al., 2013; Cecchetto et al., 2015; Patil et al., 2014) and nonfaradaic (without any redox probe in solution) (Daniels and Pourmand, 2007; Yang et al., 2004). During electroanalytical spectroscopic measurements (faradaic or non-faradaic), the modified receptive interface of the electrode undergoes a constant DC bias which is perturbed by a relatively small amplitude voltage (normally $5-10 \mathrm{mV}$ peak to peak). When the selective target is recruited by the interface (Bedatty Fernandes et al., 2015; Patil et al., 2014) it causes changes on electrical impedance which is sensitively detected and quantified. In its ubiquitous faradaic form the analytical solution is pre-doped with a large excess of "redox probe" (Fig. 1a) and an associated charge transfer resistance $\left(R_{c t}\right)$ is typically obtained by fitting the acquired impedance data (Fig. 1b) to a Randles equivalent circuit model. The $R_{c t}$ is traditionally used as a transducer sensing parameter (Bhavsar et al., 2009; Elshafey et al., 2013; Ionescu et al., 2010; Ramón-Azcón et al., 2008).

The complex capacitance data $\left[C^{*}(\omega)\right]$ derived from complex impedance $\left[Z^{*}(\omega)\right]$, in such EIS faradaic fashion, indicates the existence of dielectric (associated with double layer and other nonfaradaic effects) contribution at higher frequencies (Fig. 1c inset), which is better evidenced in the absence of a solution phase redox probe, where normally non-faradaic traditional analyses utilize the modulus of impedance $(|Z|)$, double layer capacitance $\left(C_{d l}\right)$ or phase $(\phi)$ as sampling transducer terms (Bart et al., 2005; Chuang et al., 2011; Daniels and Pourmand, 2007; Lin et al., 2010; Qureshi et al., 2010). In an opposite manner to faradaic EIS, ECS approach applies the redox reporter within the biological receptive layer as illustrated in Fig. 1d (e.g. by using mixed self-assembled monolayers containing both ferrocenethiol redox and biological receptor centers) and the measured 

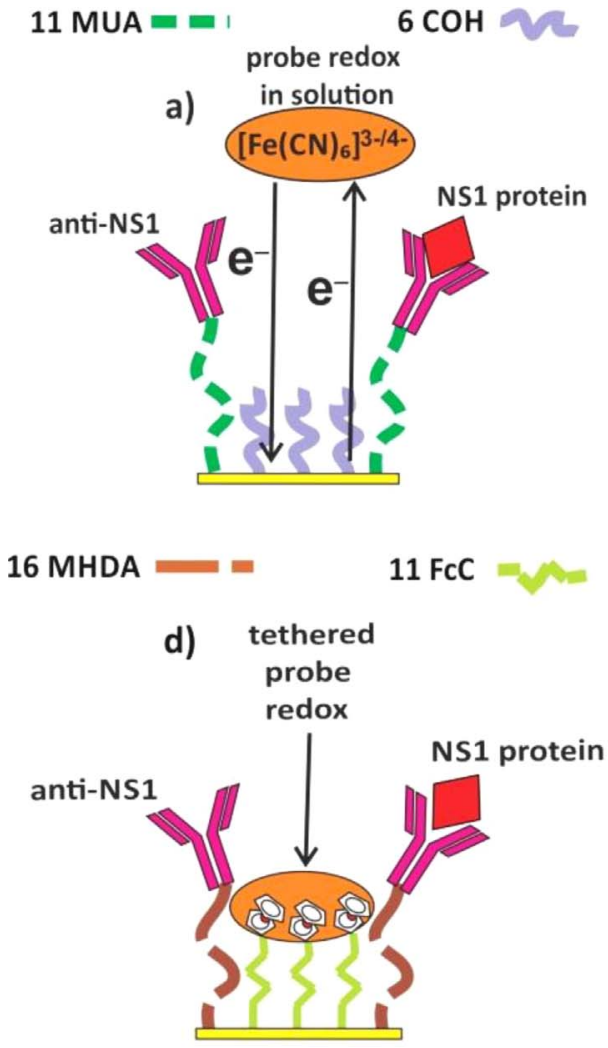
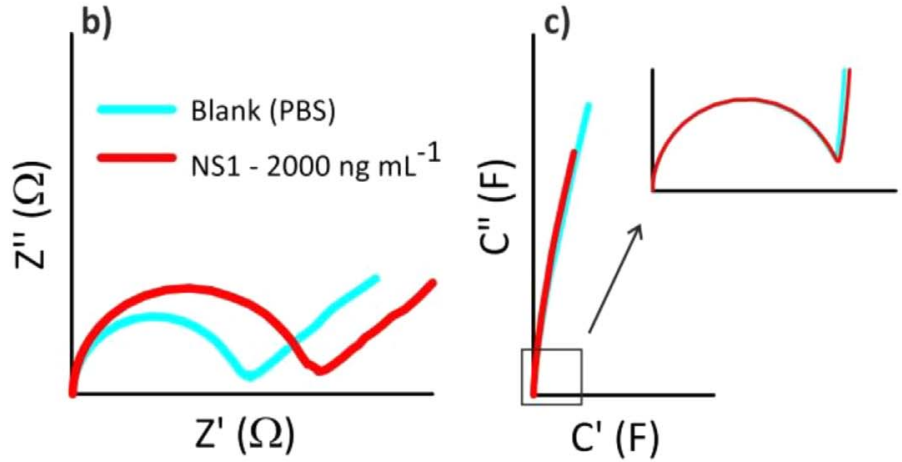
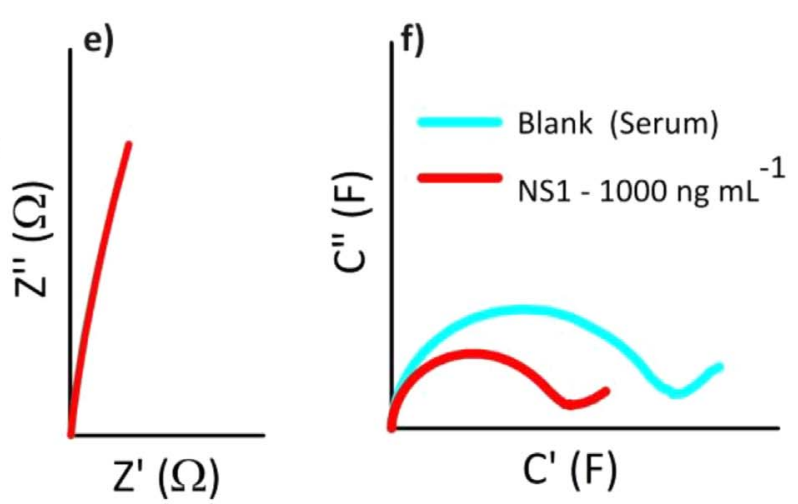

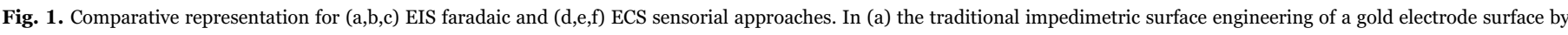

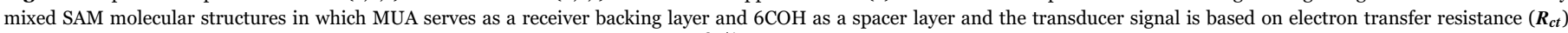

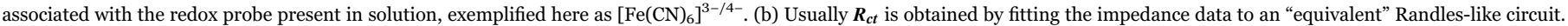

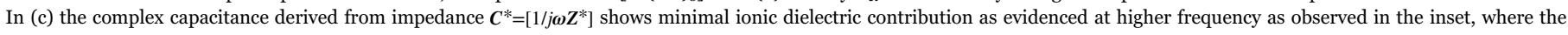

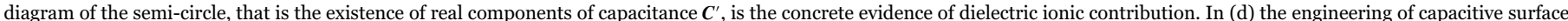

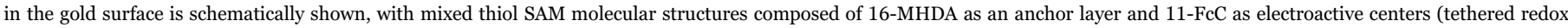

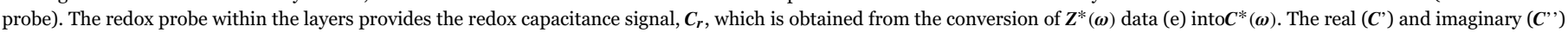
components of capacitance are represented in the Nyquist capacitive plot showed in (f).

impedance data $\left[Z^{*}(\omega)\right]$ is converted into complex capacitance by the relationship $C^{*}(\omega)=1 /\left[j \omega Z^{*}(\omega)\right]$ (Figs. 1e and f, respectively). Additional information is available in regard to redox capacitive signal/term. Thus in redox tagged receptive interfaces a supercapacitance phenomenon is observed associated with the confined redox centers (named as electrochemical or redox capacitance, $C_{r}$ ). The values of $C_{r}$ depend mostly on the redox density of states concentration associated with the redox molecular coverage. When target binding events occur, there is a perturbation on the electrochemical activity associated with the $C_{r}$ signal, as illustrated in Fig. 1f, thus enabling sensitive analytical curves to be constructed using $C_{r}$ as an effective transduction signal (Fernandes et al., 2015, 2013; Lehr et al., 2014; Marques et al., 2015; Santos and Bueno, 2016; Santos et al., 2014, 2015a, 2015b). In other words, capacitive approach has the advantage of not requiring the redox probe pre-doping of the biological samples, making it particularly appealing for point-of-care applications (Patil et al., 2014). Hence the use of ECS in diagnostic assays has been effectively demonstrated within label-free standards and being highly specific to target biomarkers, presenting good reproducibility and high sensitivity (at nano to picomolar ranges) (Fernandes et al., 2015, 2013; Lehr et al., 2014; Marques et al., 2015; Santos and Bueno, 2016; Santos et al., 2014, 2015a, 2015b).

The main focus of the present work is to compare the analytical performance of the impedimetric and capacitive methodologies for the detection of Flavivirus NS1 glycoprotein in different environments, such as phosphate buffer saline (PBS) and neat serum. We have used specifically NS1 dengue virus glycoprotein as the biological model. The appropriate application of capacitive or impedimetric sensing approaches was demonstrated to be dependent on how the redox probe amplifier signal is used concomitantly with the designing of the biological target receptive layers. Electrochemical capacitive assays were based on mixed self-assembled monolayers (SAMs) composed of 16-mercaptohexadecanoic acid (16-MHDA), used for covalent binding of NS1-antibody, and 11-ferrocenyl-undecanethiol (11-FcC), used as electroactive spacer (confined redox probe), whereas non-electroactive mixed SAM composed of 11-mercaptoundecanoic acid (MUA) functionalized with NS1-antibody (MUA-Ab) and 6-mercapto-1-hexanol $(6 \mathrm{COH})$ as spacer was applied in impedimetric assays. Parameters as sensitivity, limit of detection (LoD), relative standard deviation (RSD), repeatability, linear range and affinity constant $\left(K_{a}\right)$ between target and the receptive layer were also calculated and compared amongst the signal transduction methods (capacitive and resistive). It will be further demonstrated that capacitive assays display advantages beyond surface chemistry configurations as those regarding analytical performance, even in neat serum.

\subsection{Theoretical concepts and background}

EIS and ECS are sustained on the same mathematical principles, i.e. on the measurement of interfacial electrical transfer function that is obtained by the ratio between the oscillatory perturbation of voltage input and current output signals. From the applied modulating potential $\left[V(t)=\bar{V}+\tilde{V} e^{j \omega t}\right]$ and the resulting sinusoidal current response $\left[I(t)=\bar{I}+\tilde{I} e^{j(\omega t-\phi)}\right]$ the electrical transfer function known as 
complex impedance function $Z^{*}(\omega)$ is obtained as the quotient of $V(t)$ and $I(t)$ signals. From $Z^{*}(\omega)$ "interdependent" complex functions are acquired, such as the particular examples of complex capacitance $C^{*}(\omega)$, complex modulus $M^{*}(\omega)$ and complex admittance $Y^{*}(\omega)$ (all these termed as immittance functions) with their phasorial relationships derived without any reference to an assumed equivalent circuit or physical chemistry picture (Fernandes et al., 2015; Patil et al., 2014). The immittance function approach was successfully applied for biosensing using either redox confined (Fernandes et al., 2015) or redox free (Patil et al., 2014) interfacial architectures. Although immittance function spectroscopy is highly general, just the parameters within a clear physical meaning such as $R_{c t}$ and $1 / C_{r}$ will be herein evaluated in order to carry out the comparison of the analytical performance between ECS and traditional EIS approaches, respectively.

When analyzing the corresponding transfer function by ECS, $Z^{*}(\omega)$ signal (Fig. 1e) is mathematically converted to $C^{*}(\omega)$ from where the redox capacitive signal, $C_{r}$, can be readily obtained by Nyquist or Bode diagram analysis (Bueno et al., 2012) (Fig. 1f). Experimental details of capacitive assay approach are described in the SI document Section S1.

\section{Experimental procedures}

All reagents described in this work were purchased from SigmaAldrich, except the recombinant dengue virus NS1 glycoprotein (ab64456), monoclonal antibody anti-NS1, IgG1 isotype (ab138696) that were purchased from Abcam.

\subsection{Surface engineering of impedimetric and capacitive biosensors}

Firstly, the electrodes were mechanically and electrochemically polished as described in the SI document Section S2. EIS and ECS spectroscopies are different as analytical approaches. Each needs specific surface architectures according to the use of resistance or capacitance as the transducer signal. Regardless of the operational mechanism, we have constructed NS1 recruiting interfaces. In this work the surface strategically engineered to ECS analysis was named ECS-ES and the surface constructed to EIS analysis was named EIS-ES (see Fig. 1 for illustrative information).

The freshly cleaned $\mathrm{Au}$ electrodes were immersed in a mixed solution containing the appropriate thiols in ethanol P.A. for $16 \mathrm{~h}$, for each type of engineered surface. On one hand, EIS-ES was assembled by immersing $\mathrm{Au}$ electrode in a solution containing $1.0 \mathrm{mmol} \mathrm{L}^{-1}$ MUA (for covalent anti-NS1 attachment) and $1.0 \mathrm{mmol} \mathrm{L}^{-1} 6 \mathrm{COH}$ (as a spacer). The experimental details for EISES are described in previous work (Cecchetto et al., 2015). On the other hand, ECS-ES was assembled by immersing Au electrode in a mixed solution of $1.0 \mathrm{mmol} \mathrm{L}^{-1}$ 16-MHDA (for covalent anti-NS1 attachment) and $1.0 \mathrm{mmol} \mathrm{L}^{-1} 11-\mathrm{FcC}$ (used as electroactive spacer). It is worth noting that for ECS-ES, the ferrocene group was employed as a confined redox probe (Bueno et al., 2012). In both cases, after SAM formation, the electrodes were washed with alcohol, Milli-Q water (18.2 $\mathrm{M} \Omega$ at $25^{\circ} \mathrm{C}$; Millipore, Simplicity System, Bedford, MA, USA) and dried under nitrogen gas. Then, the receptive surfaces were activated using the standard EDC/NHS bioconjugation chemistry method (by immersion in a solution of $0.4 \mathrm{~mol} \mathrm{~L}^{-1} \mathrm{EDC}$ and $0.1 \mathrm{~mol} \mathrm{~L}^{-1} \mathrm{NHS}$ for $30 \mathrm{~min}$ ) prior to the covalent attachment of the antibody. Afterwards, aiming at blocking unspecific sites, the anti-NS1 functionalized electrodes were immersed in BSA $0.1 \%$ solution in PBS, $\mathrm{pH} 7.4$, for $1 \mathrm{~h}$ at $25^{\circ} \mathrm{C}$. All steps to construct the dengue NS1 recruiting surface were characterized by its respective ECS-ES or EIS-ES analysis as showed in SI document Sections S3 and S4, respectively.

In order to evaluate the stability of the systems, ECS-ES receptive molecular nanostructures were incubated in $40 \mu \mathrm{L}$ aliquots of PBS (pH 7.4) or neat serum without the target (blank response). The impedance spectra were recorded after $30 \mathrm{~min}$ of incubation, followed by washing procedure in PBS solution before electrochemical analysis; this procedure was repeated ten times over. Subsequently, the prepared ECS-ES and EIS-ES receptive nanostructures were tested for target detection by incubation in $40 \mu \mathrm{L}$ aliquots of different dilutions of dengue NS1 protein in PBS (pH 7.4) or neat serum. In order to find the linear range for both ECS-ES and EIS-ES methods, the incubation was performed using protein concentrations (in both PBS and neat serum biological samples) ranging from $5 \mathrm{ng} \mathrm{mL}^{-1}$ to $1,000 \mathrm{ng} \mathrm{mL}^{-1}$ and from $10 \mathrm{ng} \mathrm{mL}^{-1}$ to $2,000 \mathrm{ng} \mathrm{mL}^{-1}$ in ECS-ES and EIS-ES measurements, respectively. A $95 \%$ confidence interval was adopted and the analytical curve was constructed using the relationship between the relative response percentages (RR\%) and the logarithm of the target concentration, across the full concentration range, calculated as $R R_{n} \%=\left(R_{n}-R_{0}\right) / R_{0} x 100$, where $R_{0}$ is the specific interfacial response for zeroed target concentration $\left(R_{0}\right)$ or the blank response reference and $R_{n}$ is this response after incubation with target. The results were used to evaluate the affinity constant $\left(K_{a}\right)$ between anti-NS1/NS1 and the similarity of responses was estimated applying t-test for both approaches (ECS-ES and EIS-ES), as described in the literature (Mason et al., 2003; Santos and Bueno, 2016). Electrochemical characterization in ECS-ES was recorded in a supporting electrolyte of $20 \mathrm{mmol} \mathrm{L}^{-1}$ $\mathrm{TBAClO}_{4}$ (tetrabutylammonium perchlorate) dissolved in acetonitrile and $\mathrm{H}_{2} \mathrm{O}(20: 80)$ without any redox probe added in the biological sample. For EIS-ES, the electrochemical measurements were conducted with supporting electrolyte containing $1 \mathrm{mmol} \mathrm{L}^{-1}$ of $[\mathrm{Fe}(\mathrm{CN})$ 6] $]^{3-/ 4-}$ redox pair dissolved in PBS of $\mathrm{pH} 7.4$. For all the methods, CV was performed to identify the formal potential at a scan rate of $100 \mathrm{mV} \mathrm{s}^{-1}$ between $-0.2 \mathrm{~V}$ and $0.7 \mathrm{~V}$ and between $0.0 \mathrm{~V}$ and $0.7 \mathrm{~V}$ relative to $\mathrm{Ag} \mid \mathrm{AgCl}$, for impedimetric and capacitive approaches, respectively.

The correspondent LoDs were calculated according to Long and Winefordner (Long and Winefordner, 1983), that is $L o D=[(3.3 \times$ $S D)-a] / b$, where $S D$ is the standard deviation obtained by $R R \%, a$ is the linear coefficient, and $b$ is the angular coefficient (considering $R R \%$ vs. logarithm of the concentration). The repeatability was assessed using five inter-day and five intra-day replicate measurements of a $50 \mathrm{ng} \mathrm{mL}^{-1}$ standard solution in neat serum (in five different electrodes). In addition, Fetuin, which is a glycoprotein synthetized by the liver and secreted into the bloodstream, was used as control of the specificity of anti-NS1 interface at the maximum NS1 concentration tested, as described above.

\subsection{Electrochemical measurements}

An AUTOLAB potentiostat model PGSTAT30 with FRA module controlled by NOVA program was used for all electrochemical measurements. A three electrode setup was employed, consisting of a $2.0 \mathrm{~mm}$ diameter gold working electrode from METROHM, a platinum mesh counter electrode and an $\mathrm{Ag} \mid \mathrm{AgCl} 3 \mathrm{~mol} \mathrm{~L}^{-1} \mathrm{KCl}$ reference electrode. ECS-ES and EIS-ES assays were conducted in a frequency range of $10 \mathrm{mHz}$ to $1 \mathrm{MHz}$ with a RMS amplitude of $3 \mathrm{mV}$ (or $10 \mathrm{mV}$ peak to peak). The formal potential used in capacitance and impedance measurements were $\sim 0.44 \mathrm{~V}$ and $\sim 0.22 \mathrm{~V}$, respectively.

\section{Results and discussion}

\subsection{Stability control}

The stability of the redox tagged NS1-receptive interfaces was preliminarily tested as described in Section 2.1 (Surface Engineering of Impedimetric and Capacitive Biosensors). After ten measurements the receptive surface presented variation in percentage of $4 \pm 2$ and $5 \pm$ 2 for assays in PBS and in neat serum, respectively (see SI document Section S5). The test in serum also provided an important control of interfering substances generally present in the bloodstream. For example, ascorbate is an endogenous electroactive species appearing 

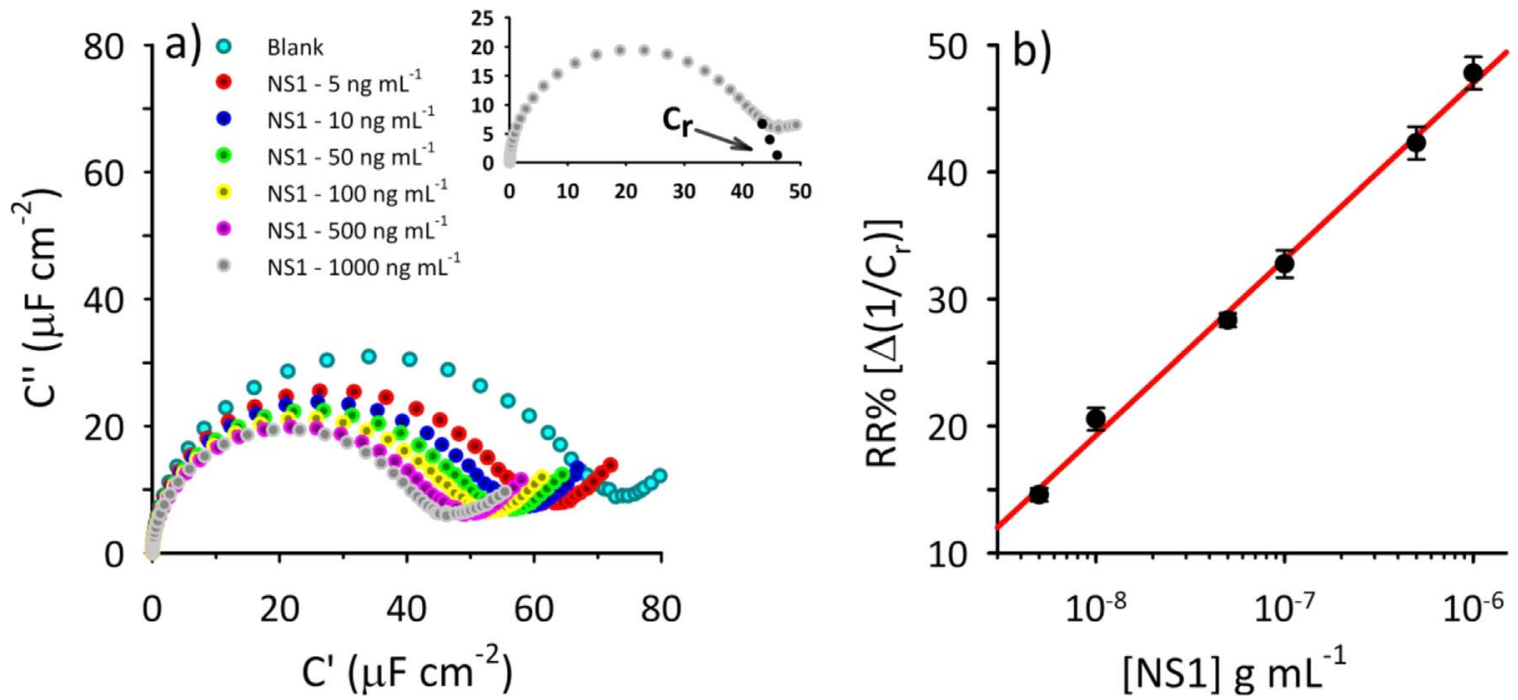

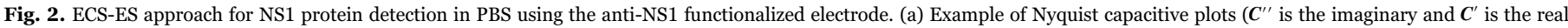

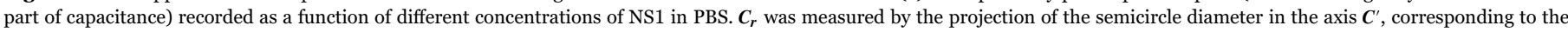

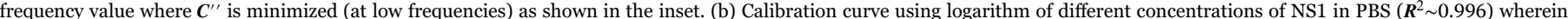

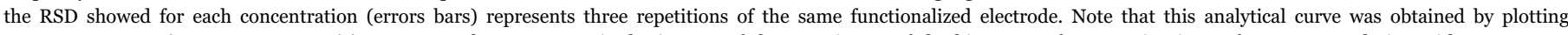

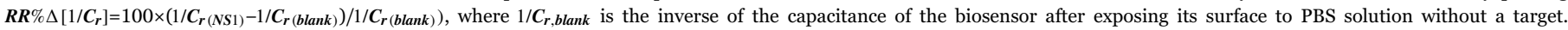
Subsequently the surface was evaluated against different concentrations of NS1 (plotted in logarithm).

in concentrations from 0.3 to $2 \mathrm{mg} \mathrm{dL}^{-1}$ (McCORMICK, 1994) that could interfere during ECS measurements. Nonetheless, the stability controls clearly confirm that additional components from serum have no significant effects upon ECS results.

\subsection{NS1 protein detection in PBS}

The redox tagged NS1-receptive interfaces used in ECS-ES measurements were exposed to increasing concentrations of NS1 in PBS from $5 \mathrm{ng} \mathrm{mL}{ }^{-1}$ to $1,000 \mathrm{ng} \mathrm{mL}^{-1}$ as shown in Fig. 2. Note that the $C_{r}$ signal decreases as NS1 concentration increases (Fig. 2a), which is associated with a decrease on the density of the electronic occupation of redox states (Bueno and Davis, 2014; Bueno et al., 2015) in the molecular receptive layer. The inverted value $\left(1 / C_{r}\right)$ of this transducer parameter is analytically useful as demonstrated in Fig. 2b. Comparing ECS-ES to EIS-ES (details are given in Section 2 and in reference Cecchetto et al., 2015), it can be observed that $R_{c t}$ (transducer parameter of EIS-ES) increases together with the target concentration as showed in Fig. 3a, due to an increase in the steric blockage of the surface caused by NS1 binding, resulting in a suppression of the electron transfer kinetics (Bryan et al., 2013). Analytically EIS-ES responsiveness to NS1 is comparable to ECS-ES in terms of relative percentage response, $R R \%$ (Fig. $3 \mathrm{~b}$ ), whereupon a linear range from $10 \mathrm{ng} \mathrm{mL}^{-1}$ to $2,000 \mathrm{ng} \mathrm{mL}^{-1}$ was obtained when considering the logarithm of such concentrations. The accuracy of the NS1 biosensors was tested by performing measurements for both EIS-ES and ECS-ES using three different electrodes, each of them was measured three times, statistically providing relative standard deviation (RSD) for the measurement for each NS1 concentration used.

When evaluating the analytical parameters meticulously across the observed linear range for NS1 protein detection by using ECS-ES and EIS-ES approaches, we have found sensitivities of $13.8 \%$ and $14.1 \%$ decade $^{-1}$, respectively. The LoD values obtained by ECS-ES and EIS-ES were 0.2 and $3.0 \mathrm{ng} \mathrm{mL}^{-1}$ respectively. Note that the LoD obtained by ECS-ES is approximately fifteen-fold lower. Additionally, this LoD is better than previously reported (Dias et al., 2013; Figueiredo et al., 2015) and yet similar to the electrochemical lateral flow immunosensor (ELFI) previously described by Sinawang et al. (2016) $\left(0.5 \mathrm{ng} \mathrm{mL}^{-1}\right)$ (Sinawang et al., 2016). The average RSDs (\%) were $3 \pm 1$ using ECSES against $9 \pm 6$ for EIS-ES (error bars in Figs. $2 b$ and $3 b$ ) which is within the acceptable range for biological assays (limit of 20\%). Based on the linear regression, coefficients of determination $\left(\mathrm{R}^{2}\right)$ of $\sim 0.996$ and 0.990 were obtained, which means that a directly proportional relationship between signal $\times$ logarithm of the target concentration exists within $99.6 \%$ and $99.0 \%$ certainty for ECS-ES and EIS-ES subsequently.

The binding affinity constant $\left(K_{a}\right)$ is a useful parameter in order to compare the biocompatibility of different surfaces acting as receptors for specific biomarkers. $K_{a}$ can be calculated by the quotient of the slope and the linear coefficient obtained from the calibration curve (Fernandes et al., 2014) (from the variation of $1 / C_{r}$ or $R_{c t}$ as signal, as a function of logarithm of the target/biomarker concentration). By applying a statistic test of similarity (t-Student) in which $p=p$ value and $\alpha=$ level of significance, the $K_{a}$ were found to be similar within an interval of $95 \%$ of confidence, ( $p=0.10, \alpha=0.05$ ). The $K_{a}$ calculated values were $(4 \pm 2) \times 10^{7} \mathrm{~L} \mathrm{~mol}^{-1}$ and $(2 \pm 1) \times 10^{7} \mathrm{~L} \mathrm{~mol}^{-1}$, respectively, for ECS-ES and EIS-ES approaches in PBS. Therefore, the biological affinities of anti-NS1/NS1 are equivalent in both assays, so that they are independent of the surface engineering and chemistry applied herein.

In order to evaluate the specificity of the anti-NS1 interface by ECSES methodology, a negative control experiment was carried out by testing the interaction with a non-specific protein (Fetuin). As shown in Fig. 4, the nonspecific variation was typically less than $5 \%$ of $\Delta\left(1 / \boldsymbol{C}_{\boldsymbol{r}}\right)$ at the concentration of $1,000 \mathrm{ng} \mathrm{mL}{ }^{-1}$ (a clinically relevant level (Alcon et al., 2002)), in contrast to a response of $43 \%$ of $\Delta\left(1 / \boldsymbol{C}_{\boldsymbol{r}}\right)$ for the specific NS1 protein. Equivalently, the specificity of anti-NS1 interface by EISES measurements demonstrated a nonspecific response at the concentration of 2,000 $\mathrm{ng} \mathrm{mL}^{-1}$ (Cecchetto et al., 2015) less than 6\%, in contrast to $41 \%$ for the NS1 protein response at the same concentration. In summary, the analytical results obtained for dengue NS1 detection in PBS for both ECS-ES and EIS-ES assays exhibited high sensitivity, clinically useful LoDs and linear ranges within very satisfactory selectivity. Considering the robustness presented so far, other assays were compared in serum as the biological target matrix as described in next section.

\subsection{NS1 protein detection in serum}

When performing dengue NS1 protein detection in serum the 

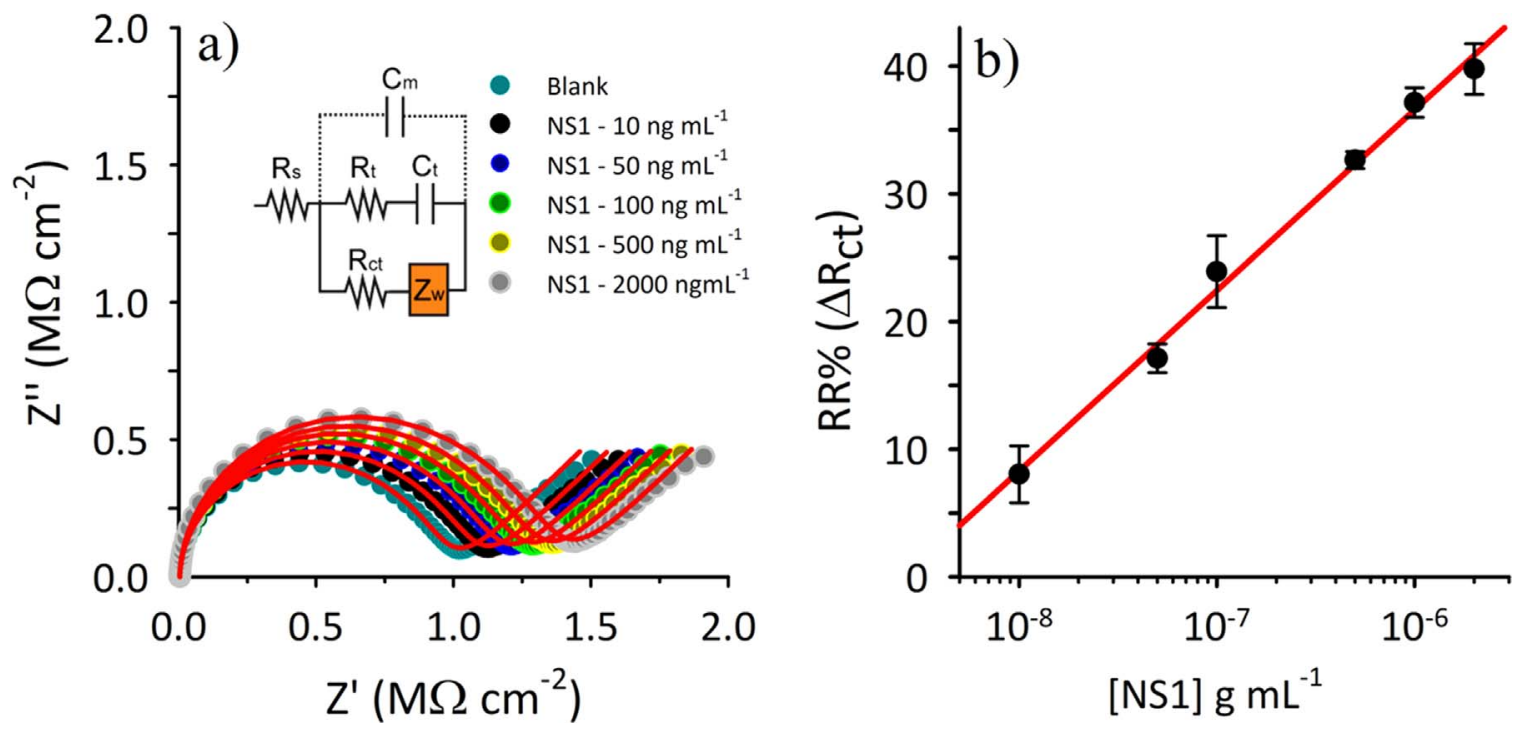

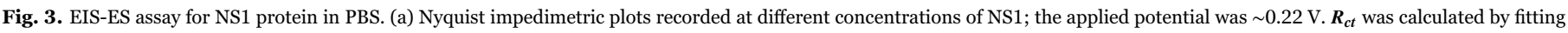

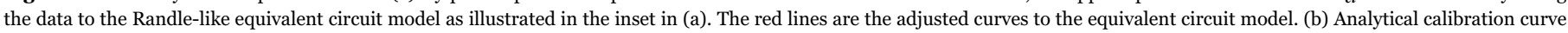
( $\left.\mathrm{R}^{2} \sim 0.990\right)$ using $\boldsymbol{R} \boldsymbol{R} \%$ against logarithm of NS1 at different concentrations with RSD (\%) represented by error bars.

Results extracted and adapted with permission from Cecchetto et al. (2015).

capacitive assay showed equivalent linear range as that observed in PBS (5-1,000 $\mathrm{ng} \mathrm{mL}^{-1}$ ), meanwhile the impedimetric assay demonstrated a decrease from $10-2,000 \mathrm{ng} \mathrm{mL}^{-1}$ (in PBS) to 10$1,000 \mathrm{ng} \mathrm{mL}^{-1}$ (in serum). The linear response for ECS-ES exhibited a coefficient of determination $\left(\mathrm{R}^{2}\right)$ of $\sim 0.98$ (Fig. 5 a) with a sensitivity of $\sim 22 \%$ decade $^{-1}$, a RSD (\%) of $7 \pm 4$ (Fig. 5a) and a LoD of $0.5 \mathrm{ng} \mathrm{mL}^{-1}$, thus approximately sixty-fold lower than those obtained by EIS-ES and ten-fold lower than an immunosensor based on EIS reported in the literature by others (Darwish et al., 2016). In addition, the repeatability of the NS1 biosensors was assessed using five interday and five intra-day replicate measurements of a $50 \mathrm{ng} \mathrm{mL} L^{-1}$ standard solution in neat serum wherein the coefficients of variation obtained were $7 \%$ and $8 \%$, for ECS, while values of $6 \%$ and $3 \%$ were achieved by EIS. These levels of precision can be considered acceptable for biological assays (Valentin et al., 2011). The obtained $K_{a}$ was $(4.0 \pm$ $0.4) \times 10^{7} \mathrm{~L} \mathrm{~mol}^{-1}$. Comparatively for EIS-ES assays in serum, $\mathrm{R}^{2}$ was 0.98 (Fig. 5b) with a sensitivity of $10.4 \%$ decade $^{-1}$, a RSD (\%) of $12 \pm 6$, LoD of $30 \mathrm{ng} \mathrm{mL}-1$ and $K_{a}$ of $(3 \pm 2) \times 10^{7} \mathrm{~L} \mathrm{~mol}^{-1}$, the latter (binding affinity) presenting a statistical similarity to that obtained by ECS-ES ( $p$ of 0.4 and $\alpha$ of 0.05 ). Independently of capacitive or impedimetric assays, the linear ranges and LoDs obtained in serum are promising for clinical applications. In primary infection patients usually present a concentration of NS1 in the bloodstream ranging from 40 to $2,000 \mathrm{ng} \mathrm{mL}^{-1}$ and in a secondary infection between 10 and $2,000 \mathrm{ng} \mathrm{mL}^{-1}$, as described by Alcon et al. (2002). All figures of merit evaluated for capacitive and impedimetric assays in PBS and in serum are summarized in Table 1. It is worth mentioning that capacitive and impedimetric assays had similar performances as evaluated by the proximity of the figures of merit.

In summary, both capacitive and impedimetric assays are suitable for the detection of NS1 to diagnose dengue based on the figures of merit such as linearity, sensitivity, RSD and negative control (selectivity), being mainly similar regarding linearity, sensitivity and affinity. Capacitive approach has the advantage of not requiring the redox probe pre-doping of the biological samples, making it particularly appealing for point-of-care testing (Bedatty Fernandes et al., 2015; Patil et al.,
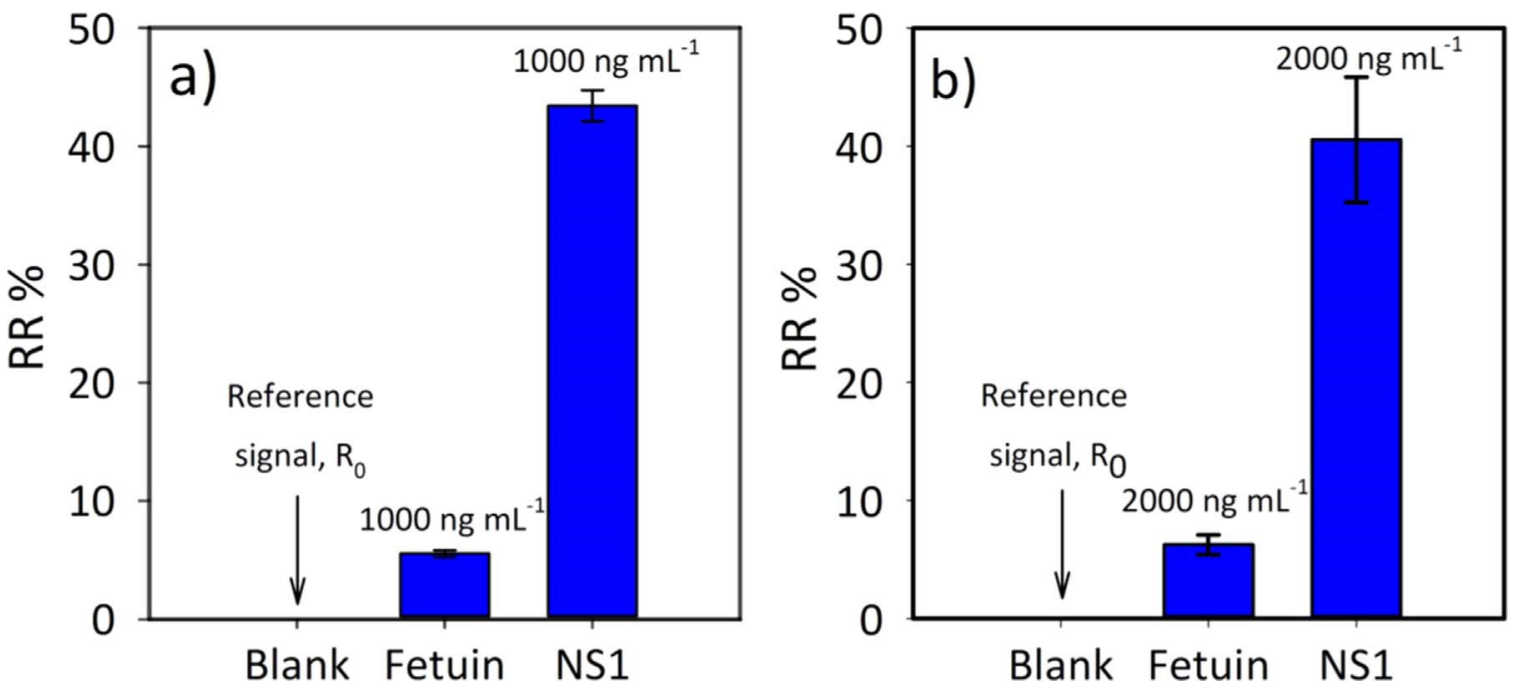

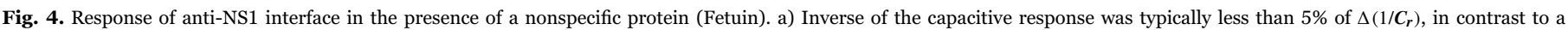

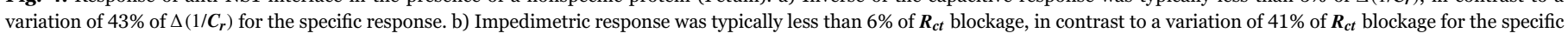
response.

Figure (b) reproduced with permission from Cecchetto et al. (2015). 

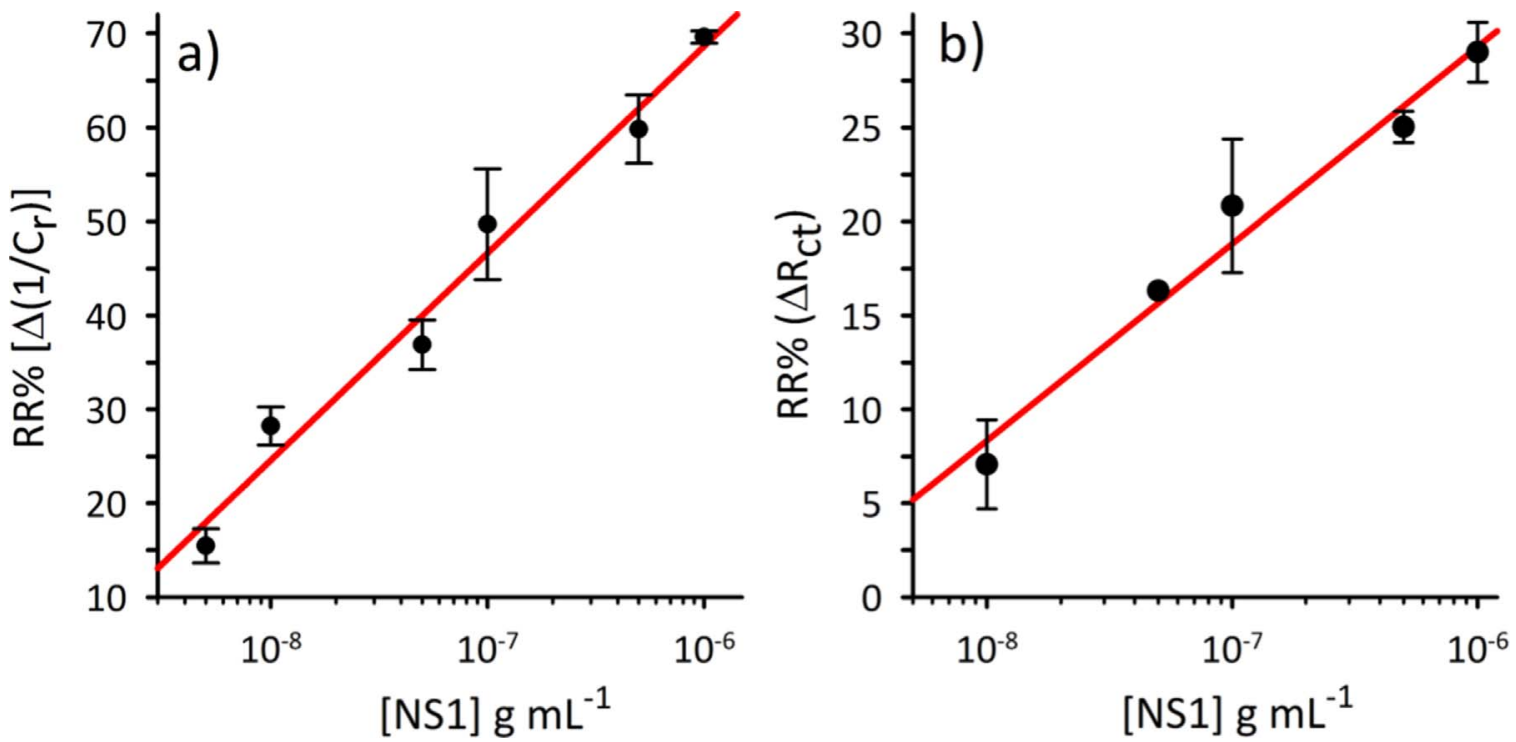

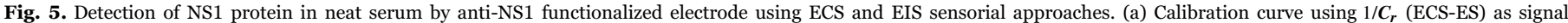

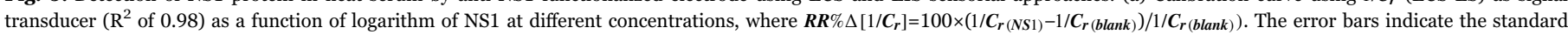
deviation of triplicate measurements. (b) Calibration curve using $\boldsymbol{R}_{c t}$ (EIS-ES) as signal transducer ( $\mathrm{R}^{2}$ of 0.98 as a function of logarithm of NS1 at different concentrations Figure "b" adapted with permission from Cecchetto et al. (2015).

Table 1

Comparison of dengue NS1 protein sensing figures of merit in PBS (pH 7.4) and neat serum.

\begin{tabular}{|c|c|c|c|c|}
\hline & \multicolumn{2}{|l|}{ EIS } & \multicolumn{2}{|l|}{ ECS } \\
\hline & $\begin{array}{l}\text { PBS } \\
\left(\mathrm{ng} \mathrm{mL} \mathrm{L}^{-1}\right)\end{array}$ & $\begin{array}{l}\text { Neat serum } \\
\left(\mathrm{ng} \mathrm{mL} L^{-1}\right)\end{array}$ & $\begin{array}{l}\text { PBS } \\
\left(\mathrm{ng} \mathrm{mL}^{-1}\right)\end{array}$ & $\begin{array}{l}\text { Neat serum } \\
\left(\mathrm{ng} \mathrm{mL} L^{-1}\right)\end{array}$ \\
\hline Linear range & $10-2,000$ & $10-1,000$ & $5.0-1,000$ & $5.0-1,000$ \\
\hline $\mathrm{R}^{2}$ & 0.990 & 0.980 & 0.996 & 0.978 \\
\hline LoD & 3.0 & 30.0 & 0.2 & 0.5 \\
\hline $\mathrm{RSD}^{*}$ & $9 \pm 6$ & $12 \pm 6$ & $3 \pm 1$ & $7 \pm 4$ \\
\hline $\begin{array}{l}\text { S (\% } \\
\left.\quad \text { decade }^{-1}\right)\end{array}$ & 14.1 & 10.4 & 13.8 & 22.0 \\
\hline$K_{a}\left(\mathrm{~L} \mathrm{~mol}^{-1}\right)$ & $(2 \pm 1) \times 10^{7}$ & $(3 \pm 2) \times 10^{7}$ & $(4 \pm 2) \times 10^{7}$ & $(4.0 \pm 0.4) \times 10^{7}$ \\
\hline intra-day (\%) & - & 3.5 & - & 5.9 \\
\hline inter-day (\%) & - & 7.1 & - & 8.1 \\
\hline
\end{tabular}

* Average of standard deviation calculated for all points in the analytical curve.

2014).

Considering that the symptoms are very similar amongst the Flavivirus infections, it is essential to advance to a differential analysis, so that the appropriate course of treatment can be followed. By using the capacitance spectroscopy platform, there is a plethora of arrays that can be engineered, including multiplexed analyses, in order to gather the excellent sensibility inherent to this electroanalytical tool together with an increased specificity provided by the biomarker itself.

\section{Conclusions}

Dengue NS1 protein biomarker was detected in PBS and serum samples using electrochemical capacitive label-free approach and compared with its counterpart (in terms of surface engineering), the traditional impedimetric methodology. In terms of figures of merit, it was demonstrated that capacitive assays are suitable even in serum biological matrix, demonstrating superior limit of detection ( $0.5 \mathrm{ng} \mathrm{mL} \mathrm{L}^{-1}$ against $30 \mathrm{ng} \mathrm{mL} \mathrm{m}^{-1}$ in impedimetric assays). The constant of affinity, $K_{a}$, was shown to be independent (i.e. statistically equivalent, as per t-Student analysis) regardless of different molecular surface engineering applied in both impedimetric and capacitive assays in which the biological affinities of anti-NS1/NS1 are equivalent in both assays. Although capacitive and impedimetric assays were clearly suitable for dengue NS1 detection in complex biological samples, capacitive assay presents an advantage, that is there is no necessity to add a redox probe to the biological samples, prior to electro analysis, which is particularly useful in minimizing (or completely avoiding) patient samples manipulation.

\section{Appendix A. Supplementary material}

Supplementary data associated with this article can be found in the online version at http://dx.doi.org/10.1016/j.bios.2016.08.097.

\section{References}

Alcon, S., Talarmin, A., Debruyne, M., Falconar, A., Deubel, V., Flamand, M., 2002. J. Clin. Microbiol. 40 (2), 376-381.

Bart, M., Stigter, E.C.A., Stapert, H.R., de Jong, G.J., van Bennekom, W.P., 2005 Biosens. Bioelectron. 21 (1), 49-59.

Bhatt, S., Gething, P.W., Brady, O.J., Messina, J.P., Farlow, A.W., Moyes, C.L., Drake, J.M., Brownstein, J.S., Hoen, A.G., Sankoh, O., Myers, M.F., George, D.B., Jaenisch, T., Wint, G.R.W., Simmons, C.P., Scott, T.W., Farrar, J.J., Hay, S.I., 2013. Nature 496 (7446), 504-507.

Bhavsar, K., Fairchild, A., Alonas, E., Bishop, D.K., La Belle, J.T., Sweeney, J., Alford, T.L., Joshi, L., 2009. Biosens. Bioelectron. 25 (2), 506-509.

Bryan, T., Luo, X., Bueno, P.R., Davis, J.J., 2013. Biosens. Bioelectron. 39 (1), 94-98. Bueno, P.R., Davis, J.J., 2014. Anal. Chem. 86 (3), 1337-1341.

Bueno, P.R., Mizzon, G., Davis, J.J., 2012. J. Phys. Chem. B 116 (30), 8822-8829.

Bueno, P.R., Feliciano, G.T., Davis, J.J., 2015. Phys. Chem. Chem. Phys..

Cavalcanti, I.T., Guedes, M.I.F., Sotomayor, M.D.P.T., Yamanaka, H., Dutra, R.F., 2012. Biochem. Eng. J. 67, 225-230.

Cecchetto, J., Carvalho, F.C., Santos, A., Fernandes, F.C.B., Bueno, P.R., 2015. Sens. Actuators B: Chem. 213 (0), 150-154.

Centers for Disease Control and Prevention. 2016. Diagnostic Testing: Molecular Test for Zika Virus.

Chikkaveeraiah, B.V., Mani, V., Patel, V., Gutkind, J.S., Rusling, J.F., 2011. Biosens. Bioelectron. 26 (11), 4477-4483.

Chikkaveeraiah, B.V., Bhirde, A.A., Morgan, N.Y., Eden, H.S., Chen, X., 2012. ACS Nano $6(8), 6546-6561$.

Chuang, Y.-H., Chang, Y.-T., Liu, K.-L., Chang, H.-Y., Yew, T.-R., 2011. Biosens. Bioelectron. 28 (1), 368-372.

D.B.G., McCORMICK, H.L., 1994 Vitamins: Ascorbic Acid., 2. ed. ed. W.B. Saunders Filadélfia.

Daniels, J.S., Pourmand, N., 2007. Electroanalysis 19 (12), 1239-1257.

Darwish, N.T., Alrawi, A.H., Sekaran, S.D., Alias, Y., Khor, S.M., 2016. J. Electrochem. Soc. 163 (3), B19-B25.

Dias, A.C.M.S., Gomes-Filho, S.L.R., Silva, M.M.S., Dutra, R.F., 2013. Biosens. Bioelectron. 44, 216-221.

Dussart, P., Labeau, B., Lagathu, G., Louis, P., Nunes, M.R.T., Rodrigues, S.G., StorckHerrmann, C., Cesaire, R., Morvan, J., Flamand, M., Baril, L., 2006. Clin. Vaccin. Immunol. 13 (11), 1185-1189. 
Elshafey, R., Tlili, C., Abulrob, A., Tavares, A.C., Zourob, M., 2013. Biosens. Bioelectron. 39 (1), 220-225.

Estofolete, C.F., Terzian, A.C.B., Parreira, R., Esteves, A., Hardman, L., Greque, G.V., Rahal, P., Nogueira, M.L., 2016. J. Clin. Virol. 81, 25-30.

Fernandes, F.C.B., Góes, M.S., Davis, J.J., Bueno, P.R., 2013. Biosens. Bioelectron. 50 (0), 437-440.

Fernandes, F.C.B., Santos, A., Martins, D.C., Góes, M.S., Bueno, P.R., 2014. Biosens. Bioelectron. 57 (0), 96-102.

Fernandes, F.C.Bedatty, Patil, A.V., Bueno, P.R., Davis, J.J., 2015. Anal. Chem. 87 (24), $12137-12144$

Figueiredo, A., Vieira, N.C.S., dos Santos, J.F., Janegitz, B.C., Aoki, S.M., Junior, P.P., Lovato, R.L., Nogueira, M.L., Zucolotto, V., Guimarães, F.E.G., 2015. Sci. Rep. 5, 7865.

Fredericks, A.C., Fernandez-Sesma, A, 2014. Ann. Glob. Health 80 (6), 466-475.

Guzman, M.G., Halstead, S.B., Artsob, H., Buchy, P., Farrar, J., Gubler, D.J., Hunsperger, E., Kroeger, A., Margolis, H.S., Martinez, E., Nathan, M.B., Pelegrino, J.L., Simmons, C., Yoksan, S., Peeling, R.W., 2010. Nat. Rev. Microbiol. 8, 9.

Ionescu, R.E., Gondran, C., Bouffier, L., Jaffrezic-Renault, N., Martelet, C., Cosnier, S. 2010. Electrochim. Acta 55 (21), 6228-6232.

Klungthong, C., Gibbons, R.V., Thaisomboonsuk, B., Nisalak, A., Kalayanarooj, S., Thirawuth, V., Nutkumhang, N., Mammen, M.P., Jarman, R.G., 2007. J. Clin. Microbiol. 45 (8), 2480-2485.

Lanciotti, R.S., Kosoy, O.L., Laven, J.J., Velez, J.O., Lambert, A.J., Johnson, A.J., Stanfield, S.M., Duffy, M.R., 2008. Emerg. Infect. Dis. 14 (8), 1232-1239.

Lehr, J., Fernandes, F.C.B., Bueno, P.R., Davis, J.J., 2014. Anal. Chem. 86 (5), 2559-2564.

Li, L., Zhao, H., Chen, Z., Mu, X., Guo, L., 2011. Biosens. Bioelectron. 30 (1), 261-266.

Lin, J., Wei, Z., Zhang, H., Shao, M., 2013. Biosens. Bioelectron. 41 (0), 342-347.

Lin, K.-C., Kunduru, V., Bothara, M., Rege, K., Prasad, S., Ramakrishna, B.L., 2010. Biosens. Bioelectron. 25 (10), 2336-2342.

Liu-Helmersson, J., Quam, M., Wilder-Smith, A., Stenlund, H., Ebi, K., Massad, E., Rocklöv, J., 2016. EBioMedicine.

Long, G.L., Winefordner, J.D., 1983. Anal. Chem. 55 (7), 712A-714A, 716A, 718A, 720A, 722A, 724A.

Luo, X., Davis, J.J., 2013. Chem. Soc. Rev, 42 (13), 5944-5962.

Marques, S.M., Santos, A., Gonçalves, L.M., Sousa, J.C., Bueno, P.R., 2015. Electrochim. Acta 182, 946-952.

Mason, R.L., Gunst, R.F., Hess, J.L., 2003. Statistical Design and Analysis of Experiments with Applications of Engineering and Science 2 ed. ed. John Wiley \& Sons, Inc, Canada.

Muller, D.A., Young, P.R., 2013. Antivir. Res. 98 (2), 192-208.

Ohno, R., Ohnuki, H., Wang, H., Yokoyama, T., Endo, H., Tsuya, D., Izumi, M., 2013. Biosens. Bioelectron. 40 (1), 422-426.

Pan American Health Organization, 2015. Description of the Current Epidemiological Trends of Dengue in the Americas.
Parkash, O., Hanim Shueb, R., 2015. Viruses 7 (10), 5410-5427.

Patil, A.V., Bedatty Fernandes, F.C., Bueno, P.R., Davis, J.J., 2014. Anal. Chem..

Peeling, R.W., Artsob, H., Pelegrino, J.L., Buchy, P., Cardosa, M.J., Devi, S., Enria, D.A.,

Farrar, J., Gubler, D.J., Guzman, M.G., Halstead, S.B., Hunsperger, E., Kliks, S.,

Margolis, H.S., Nathanson, C.M., Nguyen, V.C., Rizzo, N., Vazquez, S., Yoksan, S., 2010. Nat. Rev. Microbiol. 8.

Pournaghi-Azar, M.H., Ahour, F., Hejazi, M.S., 2009. Electroanalysis 21 (16), $1822-1828$.

Qureshi, A., Gurbuz, Y., Kallempudi, S., Niazi, J.H., 2010. Phys. Chem. Chem. Phys. 12 (32), 9176-9182.

Ramón-Azcón, J., Valera, E., Rodríguez, Á., Barranco, A., Alfaro, B., Sanchez-Baeza, F., Marco, M.P., 2008. Biosens. Bioelectron. 23 (9), 1367-1373.

Sadana, A., Sadana, N., 2015. A Fractal Analysis of Biomarkers for Different Diseases on Biosensor Surfaces. Biomarkers and Biosensors (Chapter 12). Elsevier, Amsterdam, $559-595$.

Sahab, Z.J., Semaan, S.M., Sang, Q.-X.A., 2007. Biomark. Insights 2, 21-43.

Sahoo, P., Suresh, S., Dhara, S., Saini, G., Rangarajan, S., Tyagi, A.K., 2013. Biosens. Bioelectron. 44 (0), 164-170.

Santos, A., Bueno, P.R., 2016. Biosens. Bioelectron. 83, 368-378.

Santos, A., Davis, J.J., Bueno, P.R., 2015a. J. Anal. Bioanal. Tech., S07-016.

Santos, A., Carvalho, F.C., Roque-Barreira, M.-C., Bueno, P.R., 2014. Biosens. Bioelectron. 62 (0), 102-105.

Santos, A., Piccoli, J.P., Santos-Filho, N.A., Cilli, E.M., Bueno, P.R., 2015b. Biosens. Bioelectron. 68 (0), 281-287.

Shu, P.-Y., Huang, J.-H., 2004. Clin. Diagn. Lab. Immunol. 11 (4), 642-650.

Silva, M.M.S., Dias, A.C.M.S., Cordeiro, M.T., Marques, E., Jr, Goulart, M.O.F., Dutra, R.F., 2014. Talanta 128, 505-510.

Sinawang, Prima D., Rai, V., Ionescu, R.E., Marks, R.S., 2016. Biosens. Bioelectron. 77, 400-408.

Su, C.-C., Wu, T.-Z., Chen, L.-K., Yang, H.-H., Tai, D.-F., 2003. Anal. Chim. Acta 479 (2), 117-123.

Subedi, D., Taylor-Robinson, A., 2014. Open J. Clin. Diagn. 4, 8.

Telsnig, D., Kassarnig, V., Zapf, C., Leitinger, G., Kalcher, K., Ortner, A., 2012. Int. J. Electrochem. Sci. 7 (11), 10476-10486.

Valentin, M.-A., Ma, S., Zhao, A., Legay, F., Avrameas, A., 2011. J. Pharm. Biomed. Anal 55 (5), 869-877.

Vazquez, S., Ruiz, D., Barrero, R., Ramirez, R., Calzada, N., del Rosario Peña, B., Reyes, S., Guzman, M.G., 2010. Diagn. Microbiol. Infect. Dis. 68 (1), 46-49.

Venkatanarayanan, A., Keyes, T.E., Forster, R.J., 2013. Anal. Chem. 85 (4), 2216-2222.

World Health Organization. 2016. Global Strategy for Dengue Prevention and Control, 2012-2020.

Yan, S., He, N., Song, Y., Zhang, Z., Qian, J., Xiao, Z., 2010. J. Electroanal. Chem. 641 $(1-2), 136-140$

Yang, L., Li, Y., Erf, G.F., 2004. Anal. Chem. 76 (4), 1107-1113. 